\title{
Psychiatric comorbidity as predictor of costs in back pain patients undergoing disc surgery: a longitudinal observational study
}

Alexander Konnopka ${ }^{1 *}$, Margrit Löbner², Melanie Luppa², Dirk Heider ${ }^{1,2}$, Sven Heinrich', Steffi Riedel-Heller², Hans Jörg Meisel ${ }^{3}$, Lutz Günther ${ }^{4}$, Jürgen Meixensberger ${ }^{5}$ and Hans-Helmut König ${ }^{1}$

\begin{abstract}
Background: Psychiatric comorbidity is common in back pain patients undergoing disc surgery and increases economic costs in many areas of health. The objective of this study was to analyse psychiatric comorbidity as predictor of direct and indirect costs in back pain patients undergoing disc surgery in a longitudinal study design.

Methods: A sample of 531 back pain patients was interviewed after an initial disc surgery (T0), 3 months (T1) and 15 months (T2) using the Composite International Diagnostic Interview to assess psychiatric comorbidity and a modified version of the Client Sociodemographic and Service Receipt Inventory to assess resource utilization and lost productivity for a 3-month period prior interview. Health care utilization was monetarily valued by unit costs and productivity by labour costs. Costs were analysed using random coefficient models and bootstrap techniques.

Results: Psychiatric comorbidity was associated with significantly $(p<0.05)$ increased direct (+664 Euro) and indirect costs (+808 Euro) at T0. The direct cost difference predominantly resulted from medical health care utilization and was nearly unchanged at T2. Further important cost predictors were clinical variables like the presence of chronic medical disease, the number of previous disc surgeries, and time and gender.

Conclusion: Psychiatric comorbidity presents an important predictor of direct and indirect costs in back pain patients undergoing disc surgery, even if patients do not utilize mental health care. This effect seems to be stable over time. More attention should be given to psychiatric comorbidity and cost-effective treatments should be applied to treat psychiatric comorbidity in back pain patients undergoing disc surgery to reduce health care utilization and costs associated with psychiatric comorbidity.
\end{abstract}

Keywords: Back pain, Disc surgery, Psychiatric comorbidity, Cost, Economic

\section{Background}

In industrialized societies, back pain presents a common health problem, which is often associated with disc herniation [1]. While most back pain patients with disc herniation profit from a conservative treatment surgical interventions are performed in the most severe cases, when pain and sensory or motor deficits persist under conservative treatment [2]. It is well known that back pain and back pain treatment outcome are strongly influenced by psychological factors including psychiatric

\footnotetext{
* Correspondence: a.konnopka@uke.de

${ }^{1}$ Department of Medical Sociology and Health Economics, University Medical Centre Hamburg-Eppendorf, Hamburg, Germany

Full list of author information is available at the end of the article
}

comorbidity [3-5]. Common psychiatric comorbidities in back pain patients with prevalence rates exceeding prevalence rates in the general population are affective disorders, anxiety disorders and substance abuse/dependency disorders [6,7]. Not only treatment outcome is associated with psychiatric comorbidity, but also health care costs. Several studies have found associations between psychiatric comorbidity and increased health care costs for different diseases, like dementia, substance abuse, heart failure or internal diseases [8-11]. In a recent study, Holmberg and Thelin [12] found that psychiatric comorbidity is associated with increased health care utilization in back pain patients. However, so far no study has analysed the effect of psychiatric

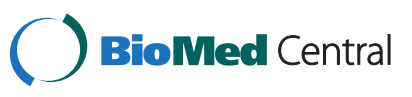


comorbidity on health care costs in patients undergoing disc surgery in a prospective study design.

Estimating the costs of an illness is useful to inform decision makers about the economic relevance of a health problem and feasible objectives for interventions. Additionally, cost-of-illness studies provide input data for further research, in particular for studies modelling cost-effectiveness of interventions. In general, costs of illness can be distinguished into direct costs and indirect costs. Whereas direct costs refer to the monetary value of utilized resources (e.g. for hospital stays, physician visits or drugs), indirect costs refer to productivity lost due to morbidity or premature mortality.

The aim of our study was to analyse predictors for direct and indirect costs in back pain patients undergoing disc surgery, and in particular the effect of psychiatric comorbidity in a prospective study design. Thereby, we hypothesised that psychiatric comorbidity is connected to increased direct as well as indirect costs.

\section{Methods}

\section{Study design and sample}

Our study referred to 620 consecutive back pain patients who underwent an index treatment of surgery for herniated disc between April 2007 and October 2008. The study received ethics committee approval by the ethics committee of the University of Leipzig. We included patients who provided informed consent, were between the age of 18 and 55 years, spoke German sufficiently and had a radiological determined herniated disc of the lumbal or cervical spine. Study participation was declined by $86(14 \%)$ of the 620 patients and 3 patients were excluded due to missing data on psychiatric comorbidity, resulting in a final sample of 531 patients. Disc surgery was either conducted at the Department of Neurosurgery at the University Hospital of Leipzig $(\mathrm{N}=149,28 \%)$, the Department of Neurosurgery at the Hospital St. Georg, Leipzig ( $\mathrm{N}=153,29 \%)$ or the Department of Neurosurgery at the Hospital "Bergmannstrost", Halle $(\mathrm{N}=229,43 \%)$. After disc surgery, all patients were offered a rehabilitation to prepare return to work which was rejected by 33 patients $(7 \%)$ of 485 non-drop-out patients available at T1. Included patients were interviewed face-to-face by experienced and trained psychologists about psychiatric comorbidity and health care utilization approximately 3.63 (SD 2.83) days after disc surgery (T0). Follow up interviews were conducted 3 months (T1) and 15 months (T2) post treatment via telephone.

\section{Instruments}

\section{Socio-demographic and illness-related variables}

As sociodemographic variables, age, gender, education, living situation, marital and employment status were assessed. Patients were classified according to the type of disc herniation (cervical or lumbar) and were asked about the number of previous disc herniations as well as previous disc surgeries in their case history. Furthermore, presence and nature of other chronic medical diseases were assessed.

\section{Psychiatric comorbidity}

We assessed psychiatric comorbidity with a German version of the Composite International Diagnostic Interview (CIDI) [13]. The CIDI is a standardized, fully structured diagnostic interview for the assessment of mental disorders that provides current and lifetime diagnoses according to the definitions of ICD-10 and DSM-IV. For the purpose of our study retrospective 6-month prevalence data were assessed at baseline. We assessed the CIDI sections for affective, anxiety and substance related disorders as the most common comorbid conditions in backpain patients, as described by Härter et al. [14]. Patients were asked probe questions on core symptoms of these psychiatric disorder groups. If such a symptom required medical attention or was sufficiently severe to affect daily life, it was scored as present, and a more detailed investigation was conducted. Finally, information on the onset and the recent nature of the particular cluster of symptoms were assessed to generate prevalence data.

\section{Resource utilization and loss of productivity}

At every measurement, resource utilization and loss of productivity were retrospectively measured for the preceding three months using a standardized questionnaire that was adapted from questionnaires used in earlier studies [15-23]. Hence T0 covered a 3 month period prior the surgical intervention, T1 covered the 3 months following the surgical intervention and T2 covered a 3 month period starting 1 year after the surgical intervention. We assessed utilization of inpatient treatment, rehabilitation, outpatient physician and non-physician services, medical goods and dentures, drugs, transports to medical treatment and informal care by relatives and/ or friends. We further assessed loss of productivity due to sickness absence days, early retirement, time spent for treatments and productivity reduction at work. Patients were asked to indicate their disease related productivity reduction at work on a scale ranging from "no reduction of productivity" to "unable to work".

\section{Cost calculation}

Costs were calculated from a societal perspective by valuing resource utilization by corresponding unit costs and productivity losses by age and gender specific labour costs. For index treatment individual hospital billing information were available and used to calculate rates for diagnoses related groups (DRG) [24,25]. Other hospital 
treatments and the post-surgery rehabilitation were valued by hospital-type specific mean rates per diem [26,27]. Outpatient physician and non-physician visits were valued by type specific costs per contact [26,28]. Drug costs were calculated using prices from the German catalogue of drugs "red list" [29]. For drugs not listed in the red list, as well as medical goods and dentures we used market prices. Informal care was valued by average German net earnings [26] representing the opportunity costs of leisure time. Costs for transportation were asked from the patients, except for car use which was valued by 0.30 Euro per kilometre according to the German income tax act [30]. Lost productivity was valued by age and gender specific gross earnings [31] plus additional employer payments for social insurances [32]. Except for medical goods, dentures and pharmaceuticals not listed in the red list, all costs refer to the year 2007 (year of measurement). For medical goods, dentures and pharmaceuticals not listed in the red list, prices were obtained from an internet based research for actual market prices. These prices refer to 2008 and 2009, corresponding to the specific time point of the searches. Unit costs originally estimated before 2007 were inflated to 2007 values using the German consumer price index [33] for direct costs and the growth rate of earnings in Germany [34] for indirect costs.

\section{Lost to follow up analyses}

From the 531 patients included at T0, 485 (91\%) were available for interviews at T1 and 286 at T2 (54\%). All patients lost at T1 and 88 of the patients lost at T2 were drop outs, whereas 157 of the patients lost at T2 were not interviewed because of study end. There were no significant differences between complete follow up participants $(\mathrm{N}=286)$ and patients lost to follow up $(\mathrm{N}=245)$ regarding disc location, gender, age, psychiatric comorbidity, presence of chronic medical disease, the number of previous disc herniations or surgeries, number of children, education, marital status, living status or employment status at baseline. The only significant $(\mathrm{p}<.05)$ difference was for type of health care insurance with patients lost to follow up being more often members of the statutory health insurance.

\section{Missing values}

To be able to calculate overall direct and indirect costs for a sufficient sample size, we were forced to replace missing values for single variables. Table 1 shows maximum percentages of missing values for single cost categories. For most variables a maximum of three percent of values was missed, except for the DRG rates of index treatment $(21 \%$ missings $)$ and the number of drug packages used $(9.6 \%$ missings at $\mathrm{T} 1,7.0 \%$ missings at T2). Missed DRG rates were replaced by the diagnosisspecific (lumbal or cervical) mean. Due to the very large heterogeneity of drugs consumed, we decided to stay conservative and replaced missing numbers of drug packages by a value of one. For all other variables, missing values of an indicated utilization were replaced by the mean utilization of respective users. If, for example, a patient indicated outpatient physician visits but not the number of visits, we replaced this missing value by the average number of visits of physician visitors.

\section{Statistical analysis}

Differences in sociodemographic variables between patients with/without psychiatric comorbidity were analysed via $t$-test and chi-square test as appropriate. We used random coefficient models to test our hypothesis and to identify explanatory variables of direct, indirect and total costs. Since cost data are often characterized by nonnormality and right-skewness, we used bootstrap techniques (4,000 replications) to estimate standard errors [35]. Explanatory variables used were type of disc herniation, psychiatric comorbidity, time of measurement, the interaction effect of psychiatric comorbidity and time, presence of other chronic medical diseases, the number of previous disc surgeries, age, gender, education, marital status, living situation, employment status, type of health insurance (statutory health insurance or private health insurance) and the number of children. In a base case scenario, we analysed direct costs without informal care (due to the hypothetic nature of informal care costs) and indirect costs without reduction of productivity in work (due to limited validity of our assessment method). Analyses including informal care costs and reduced productivity were conducted as alternative scenario. Significance level was set at $\mathrm{p}<0.05$. Cost were calculated using PASW (PASW Statistics 18), statistical analyses were performed using STATA (STATA, Release 10.0).

\section{Results \\ Sample characteristics}

Sample characteristics are shown in Table 2. Overall, mean age was 42.4 years, $57 \%$ of patients were male, $16.2 \%$ had psychiatric comorbidity and $38.8 \%$ had comorbid chronic medical diseases. On average, every fifth patient had received a former disc surgery in the past.

The most prevelant comorbidity was depression (11\%) followed by anxiety disorders (9\%) and substance abuse disorders $(2 \%)$. There were no relevant differences in comorbidity between patients with lumbal and patients with cervical disc herniation.

We found several statistically significant differences between patients with and without psychiatric comorbidity. Overall, patients with psychiatric comorbidity were more often female, single, living alone, were more often unemployed and members of statutory health insurance. Further, in lumbal disc herniation patients with psychiatric 
Table 1 Missing values of resource utilization

\begin{tabular}{|c|c|c|c|c|c|c|}
\hline & \multicolumn{2}{|r|}{ TO } & \multicolumn{2}{|r|}{ T1 } & \multicolumn{2}{|r|}{$\mathrm{T} 2$} \\
\hline & $\mathbf{N}$ & Max \% missings & $\mathbf{N}$ & Max \% missings & $\mathbf{N}$ & Max \% missings \\
\hline Hospital fee data for DRG calculation of index treatment & 531 & 21.09 & - & - & - & - \\
\hline Other hospital related variables & 531 & 0.19 & 484 & 0.41 & 284 & 0 \\
\hline Rehabilitation related variables & - & - & 484 & 0.21 & 284 & 0 \\
\hline Outpatient physician visits & 531 & 0 & 484 & 0.41 & 284 & 0.70 \\
\hline Outpatient non-physician visits & 531 & 0.19 & 484 & 0.62 & 284 & 1.06 \\
\hline Number of drug units consumed & $1,455^{\mathrm{a}}$ & 2.27 & $635^{\mathrm{a}}$ & 9.61 & $588^{\mathrm{a}}$ & 6.97 \\
\hline Medical goods consumed & 531 & 0 & 484 & 0 & 284 & 1.06 \\
\hline Informal care related variables & 531 & 0.75 & 484 & 2.69 & 284 & 0.35 \\
\hline Transports related variables & 531 & 0.56 & 484 & 2.48 & 284 & 1.76 \\
\hline Loss of productivity related variables & $427^{b}$ & 2.34 & $357^{\mathrm{b}}$ & 2.80 & $203^{b}$ & 2.46 \\
\hline
\end{tabular}

${ }^{a}$ number and percentage refer to the overall number of drug labels reported; ${ }^{b}$ percentage refers to the number of employed.

comorbidity had statistically significant more previous disc herniation than patients without psychiatric comorbidity.

\section{Costs}

Overall, mean 3-month direct costs were 5,403 Euro (SD: 2,238 Euro) at T0, 2,862 Euro (SD: 1,932 Euro) at T1 and 811 Euro (SD: 2,191 Euro) at T2, whereas mean 3-month indirect costs were 4,130 Euro (SD: 4,083 Euro) at T0, 6,629 Euro (SD: 4,861 Euro) at T1 and 1,623 Euro (SD: 3,673 Euro) at T2.

The results of our base case regression analysis are shown in Table 3. Direct costs were strongly predicted by time and "clinical" variables (disc location, psychiatric comorbidity, chronic medical disease, number of previous disc surgeries). Time was the most prominent cost predictor due to changes in therapy over time (T1: $-2,456$ Euro; T2: -4,634 Euro). Psychiatric comorbidity at T0 was the second strongest predictor of direct costs (+664 Euro), even stronger than the presence of chronic medical disease (+467 Euro). Interaction effects of time and psychiatric comorbidity at T0 were not statistically significant for direct costs.

Also with indirect costs, clinical variables like psychiatric comorbidity at T0 (+808 Euro), chronic medical disease (+951 Euro) and the number of previous disc surgeries $(+1,142$ Euro) were important cost predictors. However, the most important cost predictors were employment status $(-4,502$ Euro if unemployed) and time (T1: +3,028 Euro; T2: -2,370 Euro). At T1, the interaction of time and psychiatric comorbidity at $\mathrm{T} 0$ reached significance level for indirect costs. Here psychiatric comorbidity at T0 was associated with a reduction in indirect costs $(-1,248$ Euro). Further significant predictors of indirect costs were the number of children $(-249$ Euro), private health insurance ( -759 Euro) and gender $(+1,572$ Euro $)$. For total costs psychiatric comorbidity at T0 (+1,469 euro), chronic medical disease (+1,417 Euro), the number of previous disc surgery $(+1,645$ Euro) and male gender $(+1,203$ Euro) were almost equally strong explanatory variables.

In the alternative scenario with informal care included in direct costs and reduction of productivity in work included in indirect costs, only few changes occurred (Table 4). There were no changes in signs of any statistical significant explanatory variable, but psychiatric comorbidity was not a significant predictor of indirect costs any more. For both direct as well as indirect costs, inclusion of the two additional cost categories resulted in a larger constant, and in partially larger effects in particular of employment status and gender.

\section{Discussion}

The aim of this study was to investigate whether psychiatric comorbidity predicts direct and indirect cost in back pain patients undergoing disc surgery and to estimate other predictors for direct and indirect costs, in a prospective study design. Summarized, we found that direct as well as indirect costs were strongly predicted by time and clinical variables including psychiatric comorbidity.

We found that psychiatric comorbidity is associated with increased direct costs, though we found almost no mental health care utilization at all measurements, i.e. psychiatric comorbidity increased non-mental health care utilization, which has also been found in other diseases [8-11]. There are several possible explanations for this finding. One may be, that psychiatric comorbidity is often either not diagnosed or not treated with psychiatric services, as shown in other studies [36,37]. Another possible explanation may be underreporting of this specific type of health care due to fear of stigma. Finally, stigma may also be a reason why patients do not utilize psychiatric treatment.

As a result of the therapeutic pathway, time was a very strong predictor of costs. At T0 direct costs were strongly 
Table 2 Sample characteristics at T0

\begin{tabular}{|c|c|c|c|c|c|c|c|c|c|}
\hline & \multicolumn{3}{|c|}{ Overall $(\mathrm{N}=531)$} & \multicolumn{3}{|c|}{ Lumbal disc $(\mathrm{N}=419)$} & \multicolumn{2}{|c|}{ Cervical disc $(\mathrm{N}=112)$} & \\
\hline & $\begin{array}{l}\text { Without psychiatric } \\
\text { comorbiditiy } \\
(\mathrm{N}=445)\end{array}$ & $\begin{array}{l}\text { With psychiatric } \\
\text { comorbidity } \\
(\mathrm{N}=86)\end{array}$ & & $\begin{array}{l}\text { Without psychiatric } \\
\text { comorbiditiy } \\
(\mathrm{N}=352)\end{array}$ & $\begin{array}{l}\text { With psychiatric } \\
\text { comorbidity } \\
(\mathrm{N}=67)\end{array}$ & & $\begin{array}{l}\text { Without psychiatric } \\
\text { comorbiditiy } \\
(\mathrm{N}=93)\end{array}$ & $\begin{array}{l}\text { With psychiatric } \\
\text { comorbidity } \\
(\mathrm{N}=19)\end{array}$ & \\
\hline Age (mean (SD)) & $42.6(7.87)$ & $41.4(8.34)$ & a & $41.8(8.05)$ & $40.5(8.78)$ & a & $45.5(6.35)$ & $44.6(5.63)$ & $\mathrm{a}$ \\
\hline $\begin{array}{l}\text { Number of children (mean } \\
\text { (SD) }\end{array}$ & $1.41(0.98)$ & $1.43(2.28)$ & a & $1.37(1.00)$ & $1.13(0.99)$ & a & $1.55(0.89)$ & $2.47(4.41)$ & a \\
\hline $\begin{array}{l}\text { Number of previous disc } \\
\text { herniations (mean (SD)) }\end{array}$ & $1.61(1.62)$ & $2.70(10.3)$ & a & $1.64(1.73)$ & $3.00(11.6)$ & $\mathrm{a}^{*}$ & $1.51(1.12)$ & $1.59(1.33)$ & a \\
\hline $\begin{array}{l}\text { Number of previous disc } \\
\text { surgery (mean (SD)) }\end{array}$ & $0.22(0.58)$ & $0.29(0.62)$ & a & $0.22(0.58)$ & $0.37(0.68)$ & a & $0.18(0.57)$ & $0(0)$ & $a^{a^{* *}}$ \\
\hline \multicolumn{10}{|l|}{ Psychiatric comorbidity } \\
\hline —ICD-10 chapter F0 (N (\%)) & - & $3(1)$ & & - & $3(1)$ & & - & $0(0)$ & \\
\hline -ICD-10 chapter F1 (N (\%)) & - & $11(2)$ & & - & $7(2)$ & & - & $4(4)$ & \\
\hline -ICD-10 chapter F3 (N (\%)) & - & $56(11)$ & & - & $44(11)$ & & - & $12(11)$ & \\
\hline —ICD-10 chapter F4 (N (\%)) & - & $47(9)$ & & - & $38(9)$ & & - & $9(8)$ & \\
\hline \multicolumn{10}{|l|}{$\begin{array}{l}\text { Self reported chronic medical } \\
\text { disease }(\mathrm{N}(\%))\end{array}$} \\
\hline —Yes (ref: No) & $170(38)$ & $36(42)$ & b & $229(65)$ & $45(67)$ & $\mathrm{b}$ & $46(49)$ & $5(26)$ & b \\
\hline \multicolumn{10}{|l|}{ Gender (N (\%) } \\
\hline —Male & $179(60)$ & $47(45)$ & $b^{*}$ & $214(61)$ & $32(48)$ & $b^{*}$ & $52(56)$ & $7(37)$ & b \\
\hline \multicolumn{10}{|l|}{ Education (N (\%)) } \\
\hline —ISCED level 2 or lower & $7(2)$ & $4(5)$ & b & $6(2)$ & $4(6)$ & b & $1(1)$ & $0(0)$ & b \\
\hline —ISCED level 3 & $306(69)$ & $57(66)$ & & $240(68)$ & $48(72)$ & & $66(71)$ & $9(47)$ & \\
\hline —ISCED level 5 or higher & $132(30)$ & $25(29)$ & & $106(30)$ & $15(22)$ & & $26(28)$ & $10(53)$ & \\
\hline \multicolumn{10}{|l|}{ Marital status (N (\%)) } \\
\hline Married (ref: alone) & $264(59)$ & $35(41)$ & $b^{* *}$ & $205(58)$ & $23(34)$ & $b^{* * *}$ & $59(63)$ & $12(63)$ & b \\
\hline \multicolumn{10}{|l|}{ Living situation (N (\%)) } \\
\hline _Living alone & $68(15)$ & $24(28)$ & $b^{* *}$ & $53(15)$ & $19(28)$ & $b^{*}$ & $15(16)$ & $5(26)$ & b \\
\hline
\end{tabular}


Table 2 Sample characteristics at T0 (Continued)

\begin{tabular}{|c|c|c|c|c|c|c|c|c|c|}
\hline $\begin{array}{l}\text {-Living with partner/ } \\
\text { parents }\end{array}$ & $364(82)$ & $58(67)$ & & $290(82)$ & $45(67)$ & & $74(80)$ & $13(68)$ & \\
\hline —Other living situation & $13(3)$ & $4(5)$ & & $9(3)$ & $3(4)$ & & $4(4)$ & $1(\%)$ & \\
\hline \multicolumn{10}{|l|}{ Employment status (N (\%)) } \\
\hline $\begin{array}{l}\text { —Employed (ref: } \\
\text { unemployed) }\end{array}$ & $371(83)$ & $54(63)$ & $b^{* * *}$ & $296(84)$ & $40(59)$ & $b^{* * *}$ & $75(81)$ & $14(74)$ & b \\
\hline \multicolumn{10}{|c|}{ Type of health insurance (N (\%)) } \\
\hline $\begin{array}{l}\text {-Statutory health } \\
\text { insurance }\end{array}$ & $381(86)$ & $81(94)$ & $b^{*}$ & $308(87)$ & $62(93)$ & b & $73(78)$ & $19(100)$ & $b^{*}$ \\
\hline _Private health insurance & $64(14)$ & $5(6)$ & & $44(13)$ & $5(7)$ & & $2022)$ & $0(0)$ & \\
\hline
\end{tabular}

${ }^{\mathrm{a}}$-test; ${ }^{\mathrm{b}}$ Chi-square test; ISCED: international standard classification of education; SD: standard deviation; ${ }^{*} \mathrm{p}<.05 ;{ }^{* *} \mathrm{p}<.01 ;{ }^{* * *} \mathrm{p}<.001$. 
Table 3 Predictors of direct, indirect and total costs; base case scenario

\begin{tabular}{|c|c|c|c|c|c|c|c|c|c|}
\hline Parameter & $\begin{array}{l}\text { Direct } \\
\text { costs }\end{array}$ & $\begin{array}{c}\text { Standard } \\
\text { error }\end{array}$ & & $\begin{array}{c}\text { Indirect } \\
\text { costs }\end{array}$ & $\begin{array}{c}\text { Standard } \\
\text { error }\end{array}$ & & $\begin{array}{l}\text { Total } \\
\text { costs }\end{array}$ & $\begin{array}{c}\text { Standard } \\
\text { error }\end{array}$ & \\
\hline Constant & 4,762 & 559 & $* * *$ & 3,998 & 768 & $* * *$ & 8,757 & 976 & $* * *$ \\
\hline Diagnosis & 478 & 128 & $* * *$ & 6.52 & 231 & & 509 & 280 & \\
\hline Psychiatric comorbidity & 664 & 265 & * & 808 & 376 & * & 1,469 & 528 & $* *$ \\
\hline T1 & $-2,456$ & 130 & $* * *$ & 3,028 & 235 & $* * *$ & 571 & 291 & * \\
\hline $\mathrm{T} 1 \times$ psychiatric comorbidity & -578 & 350 & & $-1,248$ & 600 & * & $-1,829$ & 783 & * \\
\hline T2 & $-4,634$ & 164 & $* * *$ & $-2,370$ & 288 & $* * *$ & $-6,996$ & 370 & $* * *$ \\
\hline T2 x psychiatric comorbidity & 72 & 517 & & 1,333 & 833 & & 1,355 & 1,089 & \\
\hline Chronic medical disease & 467 & 155 & $* *$ & 951 & 249 & $* * *$ & 1,417 & 317 & $* * *$ \\
\hline Number of previous disc surgeries & 503 & 141 & $* * *$ & 1,142 & 167 & $* * *$ & 1,645 & 228 & $* * *$ \\
\hline Age (centralized to mean) & -6.28 & 7.66 & & 48 & 14 & $* * *$ & 41 & 17 & * \\
\hline Gender (ref: female) & -354 & 130 & $* *$ & 1,572 & 189 & $* * *$ & 1,203 & 246 & $* * *$ \\
\hline Being married & 95 & 137 & & 363 & 273 & & 462 & 333 & \\
\hline ISCED educational level $3(r e f \leq 2)$ & 451 & 401 & & -280 & 634 & & 132 & 762 & \\
\hline ISCED educational level $5(r e f \leq 2)$ & 367 & 414 & & -790 & 665 & & -460 & 803 & \\
\hline Living situation: with partner (ref: alone) & -325 & 231 & & 87 & 359 & & -180 & 440 & \\
\hline Living situation: others (ref: alone) & -52 & 458 & & 344 & 919 & & 374 & 1,060 & \\
\hline Number of children & 64 & 59 & & -249 & 102 & * & -196 & 128 & \\
\hline Private health insurance (ref: statutory health insurance) & -57 & 139 & & -759 & 279 & $* *$ & -799 & 340 & * \\
\hline Being not employed (ref: being employed) & 238 & 196 & & $-4,502$ & 331 & $* * *$ & $-4,228$ & 409 & *** \\
\hline \multicolumn{10}{|l|}{ Model statistics } \\
\hline R2 within & 0.55 & & & 0.42 & & & 0.46 & & \\
\hline R2 between & 0.33 & & & 0.28 & & & 0.26 & & \\
\hline R2 overall & 0.46 & & & 0.34 & & & 0.36 & & \\
\hline
\end{tabular}

${ }^{*} \mathrm{p}<.05 ;{ }^{* *} \mathrm{p}<.01 ; * * \mathrm{p}<.001$.

influenced by acute disease and in particular by disc surgery resulting in the highest three month health care costs of all measurements. Acute disease and disc surgery were both also associated with sickness absence causing high indirect costs at T0. At $\mathrm{T} 1$ direct costs primarily resulted from inpatient rehabilitation and subsequent outpatient treatments, resulting in considerably lower direct costs compared to T0. Indirect costs strongly increased at T1 due to more sickness absence days resulting from postoperative sick leave and inpatient rehabilitation which lasted several weeks. At T2 acute treatment and rehabilitation had been completed and direct costs preliminary consisted of outpatient treatment costs, resulting in the lowest three month health care costs of all periods analysed. Accordingly, most patients were back to work again and sickness absence (and indirect costs) declined considerably.

Though mostly not significant, the interaction term of time and psychiatric comorbidity showed an identical interesting course over time for direct and indirect costs: at T0 patients with psychiatric comorbidity showed higher costs than patients without; at T1 this difference diminished, but was found again at T2. In our opinion, this course could be seen as an artefact resulting from the rather strictly organised therapy flow during the 3-month interval preceding the $\mathrm{T} 1$ assessment. This interval was characterized by the postoperative therapy and an inpatient rehabilitation lasting mostly three to four weeks, which both are highly standardized. On the one hand this limited patient's choice of health care utilization and thus equalized direct costs of patients with and without psychiatric comorbidity. On the other hand, relative standardized durations of postoperative sick leave and rehabilitation, may also have equalized indirect costs of patients with and without psychiatric comorbidity. However, at T2 this "effect" of therapy was not present anymore; hence the impact of psychiatric comorbidity on direct as well as indirect costs was observable again. In conclusion the impact of psychiatric comorbidity on cost seems to have persisted after disc surgery and rehabilitation.

Besides time and psychiatric comorbidity, direct and indirect costs were also significantly associated with the number of previous disc surgeries: the more disc surgeries patients received in the past, the higher costs occurred. Having multiple disc surgeries indicates a worse 
Table 4 Predictors of direct, indirect and total costs including monetarily valued informal care and reduced productivity at work

\begin{tabular}{|c|c|c|c|c|c|c|c|c|c|}
\hline Parameter & $\begin{array}{l}\text { Direct } \\
\text { costs }\end{array}$ & $\begin{array}{c}\text { Standard } \\
\text { error }\end{array}$ & & $\begin{array}{l}\text { Indirect } \\
\text { costs }\end{array}$ & $\begin{array}{c}\text { Standard } \\
\text { error }\end{array}$ & & $\begin{array}{l}\text { Total } \\
\text { costs }\end{array}$ & $\begin{array}{l}\text { Standard } \\
\text { error }\end{array}$ & \\
\hline Constant & 6,388 & 869 & $* * *$ & 6,915 & 635 & $* * *$ & 13,269 & 1,176 & $* * *$ \\
\hline Diagnosis & 381 & 158 & * & -28 & 205 & & 371 & 277 & \\
\hline Psychiatric comorbidity & 893 & 352 & $*$ & 448 & 327 & & 1,348 & 549 & * \\
\hline T1 & $-2,450$ & 166 & $* * *$ & 994 & 201 & $* * *$ & $-1,453$ & 283 & *** \\
\hline T1 x psychiatric comorbidity & -564 & 454 & & -688 & 499 & & $-1,242$ & 755 & \\
\hline T2 & $-5,063$ & 192 & $* * *$ & $-3,112$ & 282 & $* * *$ & $-8,167$ & 368 & $* * *$ \\
\hline T2 $x$ psychiatric comorbidity & 38 & 709 & & 1,646 & 762 & * & 1,643 & 1,133 & \\
\hline Chronic medical disease & 643 & 191 & $* * *$ & 811 & 229 & $* * *$ & 1,397 & 329 & $* * *$ \\
\hline Number of previous disc surgeries & 548 & 162 & $* * *$ & 1,197 & 147 & ** & 1,755 & 232 & $* * *$ \\
\hline Age (centralized to mean) & -9.50 & 10.30 & & 67 & 12.40 & $* * *$ & 58 & 17.69 & $* *$ \\
\hline Gender (ref: female) & -871 & 158 & $* * *$ & 2,237 & 167 & $* * *$ & 1,343 & 247 & *** \\
\hline Being married & 104 & 181 & & 499 & 262 & & 594 & 354 & \\
\hline ISCED educational level 3 (ref $\leq 2)$ & -484 & 711 & & 256 & 521 & & -209 & 972 & \\
\hline ISCED educational level 5 (ref $\leq 2)$ & -681 & 729 & & -160 & 550 & & -829 & 1,009 & \\
\hline Living situation: with partner (ref: alone) & -212 & 269 & & -100 & 337 & & -260 & 470 & \\
\hline Living situation: others (ref: alone) & 580 & 646 & & 689 & 929 & & 1,333 & 1,233 & \\
\hline Number of children & 87 & 79 & & -328 & 90 & $* * *$ & -235 & 130 & \\
\hline Private health insurance (ref: statutory health insurance) & -40 & 165 & & -740 & 255 & ** & -775 & 326 & * \\
\hline Being not employed (ref: being employed) & 691 & 269 & * & $-7,025$ & 323 & $* * *$ & $-6,347$ & 462 & *** \\
\hline \multicolumn{10}{|l|}{ Model statistics } \\
\hline R2 within & 0.48 & & & 0.46 & & & 0.53 & & \\
\hline R2 between & 0.33 & & & 0.52 & & & 0.35 & & \\
\hline R2 overall & 0.41 & & & 0.48 & & & 0.43 & & \\
\hline
\end{tabular}

${ }^{*} \mathrm{p}<.05 ;{ }^{* *} \mathrm{p}<.01 ;{ }^{* * *} \mathrm{p}<.001$.

health state, e.g. due to a chronic back pain disease with more severe spine involvement or more complicated surgery conditions. This may result in higher direct costs due to more treatments and higher indirect costs due to more sickness absence.

Our regression analysis showed significant associations of direct and indirect costs with gender. Female gender was associated with higher direct but lower indirect costs. A deeper view into direct costs showed that women had higher costs in almost all cost categories for lumbal and cervical disc herniations regardless of psychiatric comorbidity being present or not. One possible explanation for this finding may be that women in our sample were in worse health states. Women had more often comorbid chronic medical conditions ( $44 \%$ vs. $35 \%$ ) and received on average more previous disc surgeries (0.29 vs. 0.19). Both variables were associated with higher direct costs in the regression analysis which may partially explain the gender effect. For indirect costs, we interpret the finding of lower costs in women - at least in part - as an artefact resulting from lower productivities applied for the monetary valuation of lost productivity time.

Interestingly, indirect costs were significantly $(\mathrm{p}<0.05)$ negatively associated with the number of children and private health insurance. We interpret these two findings as results of selection bias. On the one hand, one could assume that patients with children have more pressure to return to work, which may result in reduced indirect costs. On the other hand members of private health insurance tend to be healthier due to risk selection of private insurers. Further, members of private health insurance in Germany often earn higher income or are self-employed which both may be incentives to return to work fast.

In our base case analysis we excluded direct informal care costs and indirect costs resulting from reduced productivity at work. Costs of informal care were excluded because they are somewhat hypothetic: informal care costs present monetarily valued care time of relatives or friends [38]. Thus - in contrast to all other direct costs - no "real" money is paid. Instead, informal care costs represent 
the opportunity costs of leisure time lost by relatives or friends. Productivity reduction at work was assessed by a ten step Likert scale ranging from "no reduction of productivity" to "unable to work" on which patients were asked to rate themselves. This scale has not been validated yet, therefore we excluded productivity reduction at work from our base case analysis too. Including these two cost categories in alternative analyses primarily resulted in clearly larger constants and larger effects of employment status and gender but no fundamental differences in results like sign changes.

Our statistical models explained a great share of the overall variance in costs, with coefficients of delimination $\left(R^{2}\right)$ ranging from 0.34 to 0.48 . One must note that these high values of $R^{2}$ are in part a result of pseudovariance generated by the variables disc location and employment status. Whereas average costs of disc surgery were 3,572 Euro for lumbal disc herniation, they were 5,618 Euro for cervical disc herniation. Indirect costs predominantly occurred in employed patients resulting in average 3-month indirect costs of 5,338 Euro for those employed compared to 1,907 Euro for those unemployed. Thus the relative high values of $R^{2}$ generated by our models should be seen with caution.

Our study has some limitations. We found relative high portions of missing values in DRG rates and the number of drug packages used. DRG coding required a complete set of variables, including hospital record data which were often not available, whereas the high portion of missings for drug packages may be due to memory effects. Our sample contained patients with cervical and lumbal disc herniations, which may bias our results. However, disease specific and sociodemographic characteristics were similar in both patient groups; furthermore we controlled for disc location in our regression analysis. Our assessment of psychiatric comorbidity was restricted to the most important CIDI sections (affective, anxiety and substance use disorders) that represent the most prevalent and costly psychiatric disorders. Further, the assessment of psychiatric comorbidity took place after the surgical intervention and may be influenced by this acute event, resulting in an overestimation of prevalence rates. Finally, some prices were not from our base year 2007 , because no prices for this year were available. Instead we were forced to use prices of 2008 and 2009 for some goods. However, the portion of costs affected by this bias was very low und should not have a significant effect on the results.

\section{Implications for clinical practice}

Our findings imply that more attention should be given to psychiatric comorbidity in the back pain patients undergoing disc surgery. Clinicians should be aware of the high prevalence rates of psychiatric comorbidity in back pain patients, in particular in the most severe cases which are treated via surgery. If applicable, they should consider the assessment of psychiatric distress and support of mental health professionals [39]. Multimodal diagnostic and therapy approaches that pay attention to psychiatric comorbidity may help to improve the outcomes of surgical therapy and to reduce the costs connected to psychiatric comorbidity.

\section{Conclusion}

We found a strong effect of psychiatric comorbidity on direct as well as indirect costs in back pain patients undergoing disc surgery. Yet utilization of psychiatric treatments was negligible. The cost effect of psychiatric comorbidity decreased during the rehabilitation period but was present again at follow up. More attention should be given to psychiatric comorbidity in disc surgery patients and mental health care services should be offered to these patients.

\section{Competing interest}

The authors declare that they have no competing interests.

\section{Authors' contributions}

AK calculated and analysed the cost data, participated in the interpretation of results and prepared the manuscript. $\mathrm{MZ}$ and $\mathrm{ML}$ prepared clinical questionnaires, collected data and participated in the interpretation of results. DH was the primary statistician and conducted all final statistical analyses. SH contributed to the health economic study design and designed the health economic questionnaire. HJM, LG and JM contributed to the study design and recruited study patients. SRH contributed to the clinical study design and management, and contributed to the interpretation of results. HHK contributed to the health economic study design and management, and interpretation of results. All authors read and approved the final manuscript.

\section{Acknowledgement}

This study has been supported by the Department of Neurosurgery at the University Hospital Leipzig, the Division of Neurosurgery Hospital St. Georg Leipzig and the Department of Neurosurgery at the Hospital

"Bergmannstrost" Halle (Saale) and received financial support by the Deutsche Rentenversicherung Bund (reference number 8011-116-31/31.81).

\section{Author details}

${ }^{1}$ Department of Medical Sociology and Health Economics, University Medical Centre Hamburg-Eppendorf, Hamburg, Germany. ${ }^{2}$ Institute of Social Medicine, Occupational Health and Public Health, University of Leipzig, Leipzig, Germany. ${ }^{3}$ Department of Neurosurgery, Berufsgenossenschaftliche Kliniken Bergmannstrost, Halle (Saale), Germany. ${ }^{4}$ Department of Neurosurgery, Hospital St. Georg gGmbH, Leipzig, Germany. ${ }^{5}$ Department of Neurosurgery, University of Leipzig, Leipzig, Germany.

Received: 12 September 2011 Accepted: 21 August 2012

Published: 3 September 2012

\section{References}

1. van Dieen $\mathrm{JH}$, Weinans $\mathrm{H}$, Toussaint HM: Fractures of the lumbar vertebral endplate in the etiology of low back pain: a hypothesis on the causative role of spinal compression in aspecific low back pain. Medical Hypothesis 1999, 53:246-252.

2. Krämer J: Bandscheibenbedingte Erkrankungen. Stuttgart: Thieme; 2004

3. Pincus T, Burton AK, Vogel S, Field AP: A systematic review of psychological factors as predictors of chronicity/disability in prospective cohorts of low back pain. Spine (Phila Pa 1976) 2002, 27:E109-E120. 
4. Linton SJ: A review of psychological risk factors in back and neck pain. Spine (Phila Pa 1976) 2000, 25:1148-1156.

5. van der Hulst M, Vollenbroek-Hutten MM, lizerman MJ: A systematic review of sociodemographic, physical, and psychological predictors of multidisciplinary rehabilitation-or, back school treatment outcome in patients with chronic low back pain. Spine (Phila Pa 1976) 2005, 30:813-825

6. Zieger M, Schwarz R, König HH, Harter M, Riedel-Heller SG: Depression and anxiety in patients undergoing herniated disc surgery: relevant but underresearched - a systematic review. Cent Eur Neurosurg 2010, 71:26-34.

7. Demyttenaere K, Bruffaerts R, Lee S, Posada-Villa J, Kovess V, Angermeyer MC, Levinson D, de Girolamo G, Nakane H, Mneimneh Z, Lara C, de Graaf R, Scott KM, Gureje O, Stein DJ, Haro JM, Bromet EJ, Kessler RC, Alonso J, Von Korff M: Mental disorders among persons with chronic back or neck pain: results from the World Mental Health Surveys. Pain 2007, 129:332-342.

8. Hochlehnert A, Niehoff D, Herzog W, Lowe B: Elevated costs of treatment in medical inpatients with psychiatric comorbidity are not reflected in the German DRG-system. Psychother Psychosom Med Psychol 2007, 57:70-75.

9. Curran GM, Sullivan G, Williams K, Han X, Allee E, Kotrla KJ: The association of psychiatric comorbidity and use of the emergency department among persons with substance use disorders: an observational cohort study. BMC Emerg Med 2008, 8:17.

10. Kunik ME, Snow AL, Molinari VA, Menke TJ, Souchek J, Sullivan G, Ashton CM: Health care utilization in dementia patients with psychiatric comorbidity. Gerontologist 2003, 43:86-91.

11. Sayers SL, Hanrahan N, Kutney A, Clarke SP, Reis BF, Riegel B: Psychiatric comorbidity and greater hospitalization risk, longer length of stay, and higher hospitalization costs in older adults with heart failure. J Am Geriatr Soc 2007, 55:1585-1591.

12. Holmberg SA, Thelin AG: Primary care consultation, hospital admission, sick leave and disability pension owing to neck and low back pain: a 12-year prospective cohort study in a rural population. BMC Musculoskelet Disord 2006, 7:66.

13. Wittchen HU, Pfister E: Instruktionsmanual zur Durchführung von DIA-X Interviews. Swets Test Services, Frankfurt: Swets \& Zeitlinger B.V; 1997.

14. Harter M, Reuter K, Weisser B, Schretzmann B, Aschenbrenner A, Bengel J: A descriptive study of psychiatric disorders and psychosocial burden in rehabilitation patients with musculoskeletal diseases. Arch Phys Med Rehabil 2002, 83:461-468.

15. Stark R, König HH, Leidl R: Costs of inflammatory bowel disease in Germany. PharmacoEconomics 2006, 24:797-814.

16. Neubauer S, Holle R, Menn P, Grassel E: A valid instrument for measuring informal care time for people with dementia. Int J Geriatr Psychiatry 2009, 24:275-282.

17. Luppa M, Heinrich S, Angermeyer MC, König HH, Riedel-Heller SG: Healthcare costs associated with recognized and unrecognized depression in old age. Int Psychogeriatr 2008, 20:1219-1229.

18. Luppa M, Heinrich S, Matschinger H, Hensel A, Luck T, Riedel-Heller SG, König HH: Direct costs associated with mild cognitive impairment in primary care. Int I Geriatr Psychiatry 2008, 23:963-971.

19. Heinrich S, Luppa M, Matschinger H, Angermeyer MC, Riedel-Heller SG, König HH: Service utilization and health-care costs in the advanced elderly. Value Health 2008, 11:611-620.

20. Luppa M, Heinrich S, Matschinger H, Sandholzer H, Angermeyer MC, König HH, Riedel-Heller SG: Direct costs associated with depression in old age in Germany. J Affect Disord 2008, 105:195-204.

21. Becker A, Seitz R, Jacobi E, Leidl R: Cost evaluation by a patient questionnaire: pilot study of a weekly cost diary. Rehabilitation (Stuttg) 2001, 40:12-20.

22. Rosch M, Leidl R, Tirpitz C, Reinshagen M, Adler G, König HH: Cost measurement based on a cost diary in patients with inflammatory bowel disease. Z Gastroenterol 2002, 40:217-228.

23. Roick C, Kilian R, Matschinger H, Bernert S, Mory C, Angermeyer MC: German adaptation of the client sociodemographic and service receipt inventory - an instrument for the cost of mental health care. Psychiatr Prax 2001, 28(Suppl 2):S84-S90.

24. AOK Bundesverband: Krankenhausbezogene Zusammenstellung der vereinbarten Basisfallwerte, Stand 10. September 2008. Berlin: AOK Bundesverband; 2008.
25. Medizincontrolling/DRG Research Group UM: DRG-Webgrouper. University of Münster: 2009. http://Drg.Uni-Muenster.De/De/Webgroup/m.Webgroup.Php (Access Several Times During 2009).

26. Krauth C, Hessel F, Hansmeier T, Wasem J, Seitz R, Schweikert B: Empirical standard costs for health economic evaluation in Germany - a proposal by the working group methods in health economic evaluation. Gesundheitswesen 2005, 67:736-746.

27. Verband deutscher Rentenversicherungsträger VDR: Statistik der Deutschen Rentenversicherung, Rehabilitation 2007 - Band 169. Würzburg: Verband Deutscher Rentenversicherungsträger; 2008.

28. Verband der Angestelltenkrankenkassen e.V: VDAK: Vergütungslisten für ambulante Leistungen, Anlage zum Vertrag über die Erbringung ambulanter Leistungen. In Verband Deutscher Angestelltenkrankenkassen E.V. http://www.Kvhb.DeNerordnungen/Heilmittel.Php (Access May 11, 2009).

29. Rote Liste 2007 Arzneimittelverzeichnis für Deutschland: Rote Liste Service GmbH. Frankfurt am Main: ECV Editic Cantor Verlag; 2009.

30. Einkommensteuergesetzbuch (EStG): Bundesgesetzblatt Teil 1. Berlin: Bundesministerium der Justiz; 2006.

31. Bundesamt S: Verdienste und Arbeitskosten 2006. Wiesbaden: Statistisches Bundesamt; 2009.

32. Bundesamt S: Arbeitskostenerhebungen - Arbeitskosten im Produzierenden Gewerbe und im Dienstleistungsbereich, Ergebnisse für Deutschland 2004. Wiesbaden: Statistisches Bundesamt; 2007.

33. Bundesamt S: Statistisches Jahrbuch 2008 für die Bundesrepublik Deutschland. Wiesbaden: Statistisches Bundesamt; 2009.

34. Bundesamt S: Verdienste und Arbeitskosten, Indizes der Arbeitnehmerverdienste 2007. Wiesbaden: Statistisches Bundesamt; 2009.

35. Efron B, Tibshirani R: Bootstrap Methods for Standard Errors, Confidence Intervals, and Other Measures of Statistical Accuracy. Stat Sci 1986, 1:54-77.

36. Harter M, Woll S, Reuter K, Wunsch A, Bengel J: Recognition of psychiatric disorders in musculoskeletal and cardiovascular rehabilitation patients. Arch Phys Med Rehabil 2004, 85:1192-7.

37. Tiemens BG, Ormel J, Simon GE: Occurrence, recognition, and outcome of psychological disorders in primary care. Am J Psychiatry 1996, 153:636-44.

38. Koopmanschap MA, van Exel JN, van den Berg B, Brouwer WB: An overview of methods and applications to value informal care in economic evaluations of healthcare. PharmacoEconomics 2008, 26:269-80.

39. Zieger M, Luppa M, Matschinger $H$, Meisel HJ, Günther L, Meixensberger J, Toussaint R, Angermeyer MC, König HH, Riedel-Heller SG: Affective, anxiety, and substance-related disorders in patients undergoing herniated disc surgery. Soc Psychiatry Psychiatr Epidemiol 2010, doi:10.1007/s00127-0100283-2.

doi:10.1186/1471-2474-13-165

Cite this article as: Konnopka et al.: Psychiatric comorbidity as predictor of costs in back pain patients undergoing disc surgery: a longitudinal observational study. BMC Musculoskeletal Disorders 2012 13:165.

\section{Submit your next manuscript to BioMed Central and take full advantage of:}

- Convenient online submission

- Thorough peer review

- No space constraints or color figure charges

- Immediate publication on acceptance

- Inclusion in PubMed, CAS, Scopus and Google Scholar

- Research which is freely available for redistribution 